\title{
WHICH RELAUNCH FOR THE WELFARE IN ITALY POST COVID-19?
}

\author{
Carmine D’Antonio
}

Responsible for the Relations with Institutions and Bodies of the National Union of Insurance Professionals (SNFIA). The opinions of the author do not commit and not are they an expression of the address of the Institute to which he belongs.

KEYWORDS: labor, welfare, Insurance

\section{ABSTRACT}

The challenge for welfare after Covid-19 will be to use the crisis in a prospective way, to govern "together" the changes that have taken place and those coming. It is a priority to involve the Trade Union in governing change, which is an urgent necessity in the face of the new season of rights and duties, linked to the changing world of labor.

\section{INTRODUCTION}

The Covid-19 pandemic that hit our country in 2020 has introduced elements for a deep break with the past.

The problems emerged during the health emergency lead us to believe that in 2021 new contents are needed for business, savings and consumption strategies. It will be necessary to renovate trust in the market, to introduce innovative methods for the organization of work, and to redesign the current "social protection", as a result of advanced industrial relations.

There is a general awareness of the importance of a new process of knowledge and planning, based on the creation of work, development and new enterprise. The relaunch of the Italian economy will necessarily rely on the Institutions and on the Trade Union. It will be fundamental to overcome individualism, leaving to collective bargaining the task of establishing precise evolutionary rules.

In this regard, the National Collective Labour Agreement, for the regulation of relations between insurance companies and employees in the nonmanagerial insurance sector, has set up a single national fund for insurance against the risks of not-self-sufficiency, operative since 2007. From a shared problem the parties have established for the Fund: governance, definition of not-self-sufficiency, benefits, etc. 1

As for the health insurance sector, the IVASS Bulletin on activity in the period 2014-20192 shows full economic sustainability. At the same time, the issue of the efficiency of expenditure is quite evident, also in consideration of the high Expense ratio3. In particular, it highlights that:

- in 2019 , total premiums written stood at 6,299 million euros, constituting $18.4 \%$ of non-life business production,

- table 1 below shows the trends in the loss ratio and expense ratio of the accident and health classes, compared with the total non-life classes. "In relation to premiums, compared with the overall averages for the Non-Life classes, there are lower outlays for claims and slightly higher management costs in the Health sector, which is therefore characterised by lower overall costs".

- the result of the technical account for direct business net of reinsurance for the health sector amounted to $€ 812$ million in 2019 , of which $€$ 675 million related to accident and $€ 137$ million to health insurance,

- $\quad 53.6 \%$ of premiums in the health line of business comes from collective policies taken out by health funds for their members, which pay premiums (an average of 171 euros) that are higher than the average for the line of business and are characterized by a higher frequency of claims, with a lower average unit cost.

Once the healthcare emergency is over, there will be a need to renew the National Collective Labor Contract for tens of millions of Italian workers, including public employees. The trade unions will have to take on a central role and be the bearers of requests to rethink

\footnotetext{
${ }^{1}$ See link https://www.ltc.ania.it/

${ }^{2}$ See link https://www.ivass.it/pubblicazioni-e-statistiche/statistiche/bollettino-statistico/index.html?com.dotmarketing. $\underline{\text { htmlpage. language }=3}$

${ }^{3}$ In the first half of 2020, a company brought to market a new flexible and modular health policy that allows the insured to have a preventive and ongoing approach, combining the ability to keep track of their health and physical activity through an IoT device, complimentary for those who purchase the policy until December 31,2020. This is a health policy that combines the reimbursement of medical expenses with a prevention plan consisting of an entry checkup and a health maintenance program with voluntary adherence: a path of preventive and personalized checks that accompanies the insured. See link https://www.ivass.it/pubblicazioni-e-statistiche/pubblicazioni/altre-pubblicazioni/2020/prodotti-i-sem-2020/ index.html? com.dotmarketing.htmlpage.language $=3$
} 


\begin{tabular}{|c|c|c|c|c|c|c|}
\hline & \multicolumn{6}{|c|}{ Accident class } \\
\hline & 2014 & 2015 & 2016 & 2017 & 2018 & 2019 \\
\hline Loss ratio & 43,8 & 41,4 & 39,9 & 39,2 & 38,6 & 39,8 \\
\hline Expense ratio(a) & 34,5 & 34,9 & 35,9 & 36,4 & 37,3 & 36,7 \\
\hline \multirow[t]{3}{*}{ Combined ratio (b) } & 78,3 & 76,3 & 75,9 & 75,6 & 75,9 & 76,5 \\
\hline & \multicolumn{6}{|c|}{ Health insurance } \\
\hline & 2014 & 2015 & 2016 & 2017 & 2018 & 2019 \\
\hline Loss ratio di bilancio & 67,9 & 67,6 & 66,9 & 67,5 & 70,4 & 70,1 \\
\hline Expense ratio(a) & 23,8 & 23,3 & 23,9 & 22,9 & 22,9 & 22,6 \\
\hline \multirow[t]{3}{*}{ Combined ratio di bilancio (b) } & 91,7 & 90,9 & 90,9 & 90,5 & 93,3 & 92,7 \\
\hline & \multicolumn{6}{|c|}{ Health sector (Accident and Health) } \\
\hline & 2014 & 2015 & 2016 & 2017 & 2018 & 2019 \\
\hline Loss ratio di bilancio & 53,9 & 52,5 & 51,6 & 51,8 & 53,3 & 54,3 \\
\hline Expense ratio(a) & 30,1 & 30 & 30,7 & 30,3 & 30,5 & 29,9 \\
\hline \multirow[t]{4}{*}{ Combined ratio di bilancio (b) } & 84 & 82,5 & 82,3 & 82,1 & 83,8 & 84,2 \\
\hline & & & & & & \\
\hline & \multicolumn{6}{|c|}{ Total non life business } \\
\hline & 2014 & 2015 & 2016 & 2017 & 2018 & 2019 \\
\hline Loss ratio di bilancio & 63,9 & 62,4 & 62,8 & 63,7 & 62,6 & 63,3 \\
\hline Expense ratio(a) & 26,2 & 27 & 27,4 & 27,6 & 27,7 & 27,9 \\
\hline Combined ratio di bilancio (b) & 90,1 & 89,4 & 90,3 & 91,3 & 90,3 & 91,2 \\
\hline
\end{tabular}

Tab. 1 - Loss, expense and combined ratio in comparison (\%)

(a) Expense ratio calculated as the percentage of operating expenses on premiums written.

(b) Combined ratio in the financial statements $=$ loss ratio in the financial statements + expense ratio.

the current model of social protection, especially in terms of health and welfare.

During the COVID-19 pandemic, in order to provide an initial response to the emergency, some specific coverage ware activated, such as allowances for hospitalizations and home isolations or reimbursements for medical services provided at home, etc.

There is a lot to say when we talk about welfare, but without work, it is certainly not possible to create wealth to distribute, nor is there any savings to be made. Work then draws collective attention to the value of duties, as these are the manifesto of dignity and individual freedom. 4

In the workplace in 2020, numerous agreements were signed between the social partners, such as safety protocols, to safeguard health. The issue of the sustainability of Italian private healthcare spending, which continues to grow, must be addressed by the social partners as part of national collective bargaining. It is necessary to recover safety and protection of the person, in order to reduce the significant social inequalities, which have been increasing significantly during the current health emergency.5

The aim of a new planning for the digital era will be to have the human being at the centre of an effective, accessible and resilient health eco-system. The challenge in Italy at this time is very demanding because it is necessary to take into account the demographic variable, the problem of widespread non-self-sufficiency, the strong "flexibility" of work, etc.

The effects of the Covid-19 pandemic have totally involved the insurance industry in the political debate. The latter has responded to the demands of the community, accompanying the market in this difficult historical phase, making its energies available for the relaunch of the country. During the months of

\footnotetext{
${ }^{4}$ See Alberto Brambilla, Le scomode verità su tasse, pensioni, sanità e lavoro, Solferino 2020.

${ }^{5}$ For an in-depth study on the governance of risks in Italian welfare see A. Coviello and C. D'Antonio, Risk management in healthcare, http://www.cnr.it/prodotto/i/407630 and C. D'Antonio and R. Lelli, IVASS Le prime misure nel mercato assicurativo per l'emergenza da Covid-19, in Notiziario SNFIA, Informazione Straordinaria - $6^{\circ}$ uscita https://www. snfia.it/2020/04/snfia-informazione-straordinaria-6/ and http://www.cnr.it/prodotto/i/409131 - La missione del settore assicurativo nelle politiche di welfare - Coviello Antonio, D’Antonio Carmine, Di Trapani Giovanni in Rivista elettronica di diritto, economia, management Anno IX, n. 3/2019 Publisher: ClioEdu - Lecce ISSN: 2039-4926 https://www.clioedu.it/ marketplace/elenco-completo/item/rivista-elettronica-di-diritto-economia-management-n-3-2019.
} 
lockdown, consumers have expressed new demands, highlighting the need to acquire new protections in step with the times. "The health emergency and the consequent restrictions - as stated with the usual clarity by the Secretary General of IVASS Stefano De Polis - have led to the emergence of new risks and new protection needs for individuals. Insurance products must primarily respond to the real protection needs of users, they must be transparent and clear in what they offer and do not offer. Consumer confidence is critical. ... The insurance industry lives on the trust that policyholders place in it."

In IVASS's experience6, innovation in "health" insurance products has been underway for a few years now, primarily through IoT and digital services. The latter are supporting and complementing traditional insurance coverages, on the one hand, to make the products themselves more comprehensive, and on the other, to enable prevention, reducing risks. The COVID-19 emergency has highlighted the need to update the contractual clauses of the products. Hence the need to rethink products from a different perspective, which cannot and must not forget to focus on the care of the human being.

Aspects to be taken into consideration when reviewing products are:

- the clarity between the different purposes of private insurance versus public health care;

- the adoption of restrictive criteria contained in the National Health Service guidelines also in the area of private healthcare. The product would then no longer be truly supplementary to the NHS;

- the precise description of the contents of the clauses (very important are those that describe how much and which coverage is guaranteed, which is excluded, what the maximum amounts are and what the limits of indemnity are);

- the clauses which are difficult to understand and which lead to a high level of litigation.

The Institute's expectation is that "Leveraging the renewed sensitivity of citizens resulting from the shock of the Covid-19 pandemic is the time to design clear products that have real value for consumers and combat underinsurance in a sector as delicate as health."

The President of IVASS, moreover, recently stated that "In the health sector there is a need to better define the forms of collaboration between public and private intervention, including a review of the structure of rules and controls on the different types of private entities operating there. ... The adoption of advanced diagnostic tools, telemedicine, the strengthening of the use of data banks can make health services more effective and efficient. They can also facilitate the offer of insurance services, with digital modalities that reduce intermediation costs, and can increase the information available to consumers." 7

The insurance sector is proposed as a key strategic welfare sector that can contribute to economic growth and social welfare of our country, continuing to represent, in new forms, a driver of its competitiveness in the current geopolitical scenarios.

Companies are a major long-term institutional investor and hold a large part of the long-term savings of Italians. Companies need the economy to move towards innovation, and to be sustainable and attentive to the protection of environmental values, also because natural catastrophes can entail enormous compensation for them. Insurers offer products to meet the real protection, health and welfare needs of families and businesses, when public intervention cannot be fully relied upon and complementary coverage is needed, with a view to increasing integration between public and private.

Elsewhere, it's pointed out that the only possible way to respect the Italian Constitution (art. 32) and guarantee a better health and economic future is to invest in public health. We need more staff and more beds, the reorganization of the entire health care system with more specializations, supplementary health care funds and LTC, incentives for the national production of equipment for intensive care, for diagnostics and new technologies in the health field, of which our country was a leader in the world.

Against this background, it would be desirable in the future a greater synergy and cooperation between public and private, in order to be closer to the problems and needs of citizens and their families.

The efficient management of individual and collective risks will require increasing recourse to mutualisation. ANIA, in the person of President Maria Bianca Farina, reminded in the 2020 Assembly that the country, if better protected from major risks, would have less need to equip itself with precautionary savings, thereby freeing up resources for investments essential for growth. It would then be a question of activating, finally, in a structured and organized manner, a partnership between public and private, providing incentives to families, also through new fiscal levers. Multiple actors consider partnerships indispensable for the future of our country in the field of supplementary health care and non-self-sufficiency, the social security purpose of savings, natural disasters, etc. The public sector alone cannot cope with this, but there are the tools and energies to build simple, clear and fair insurance coverages, which have a real value for the insured, can be promptly activated in case of need, and provide a service appropriate to the real needs of the insured.

The Secretary General of IVASS Stefano De Polis, from the point of view of supervision, has declared "We ask companies to offer insurance products tailored to customers; products sized on the real needs of users but also clear products, free from excessive complexity and not impoverished by quibbles and exclusion clauses. In this sense, the rules of the IDD are of great help to IVASS because they have outlined in a precise way the conduct that companies must take during the creation and distribution of insurance products." 8

\footnotetext{
${ }^{6}$ See link https://www.ivass.it/media/interviste/documenti/interventi/2020/04-11-dm-healt-insurance/DM_Slide_Health Insurance Summit.pdf

${ }^{7}$ See link https://www.ivass.it/media/interviste/documenti/interventi/2020/18-11-2020-df-wif/DF_Ambrosetti UnipolSai 18 novembre 2020.pdf
}

${ }^{8}$ See link https://www.ivass.it/media/interviste/intervista/intervista-de-polis-a-notiziesnfia/. 
Obviously, the evolutionary path of insurance in Italy, as for many other fundamental economic issues for the country, leverages on the role of Poste Italiane, owner of the insurance group Poste Vita. Poste is a public enterprise, since it operates under ordinary market conditions, making profits and sustaining the losses resulting from its activities. In its hands is placed a large slice of the consolidated savings of Italian families, which probably needs to be finalized to cover the new long-term needs of Italian citizens, especially in the welfare sector.

The insurance world is invested by the Insurthec phenomenon and by the increasing use of data for business reasons. Insurers manage the confidentiality of their clients' data, for the authority and reputation they have earned over time, giving their clients the freedom to decide their own future.

The scenarios are increasingly complex and technological; digitalization enters forcefully in the daily life of organizations, companies, public administration and citizens. The growth of the data produced is constantly increasing, artificial intelligence is applied in every activity, digital technology supports the development of relationships, etc. It is necessary to know how to exploit these challenges in order to create a lasting value, govern the technological lever, build our own success factors and overcome together the strong competition.

In the Italian experience, innovative start-ups have not taken on the role of true insurance companies, given the demanding regulatory and capital requirements, the operational complexities and the propensity of investors for short-term returns.

At the moment, the prevailing model is that one of partnerships between start-ups and insurance companies or between start-ups and large brokers, who see in these interactions the way to expand into business sectors that would otherwise be foreclosed or difficult to acquire.

For regulatory purposes, Insurtech-related phenomena should be partly tolerated and partly regulated, so as not to exclude innovation a priori.

Moreover, Insurtech, while favouring the gradual development of new products and innovative methods of distribution, also determines the development of new pitfalls constituted by cyber attacks companies are also constantly exposed to. It is therefore necessary to continue increasing the measures of prevention and protection against cyber risk.

EIOPA is monitoring this phenomenon and has noted that while the increasing cooperation with third parties (start-ups and BigTech companies) should bring advantages to consumers in terms of more targeted and cost-efficient products, it also entails a series of risks (operational, legal, cyber attack, data loss, reputational risk, etc.).

The widespread use of third parties can also lead to concentration risk. This case occurs when a large number of companies become dependent on a small number of outsourced service providers. See the Amazon case.

Consumers currently expect a wide range of products available, but can often find standardized products that limit overall choice.

Platforms should offer products based on customers' specific demands and needs, but, at present, the offering is tailored to the overall platform.

Other risks may also arise from the behaviour of consumers who may purchase coverage inadvertently or may not pay sufficient attention to the coverage they are purchasing, going into over- or under-insurance.

The principle-based regulatory approach seems to be the most appropriate in such a context, adopting a compliance that starts with precise rules of conduct from the conception of the product and with sanctions in the event of any violations that are highly deterrent. The latter are necessary because the real added value of managing all the complexity we experience is measured in the confidence in the risk management tools available on the market. Institutions, with their reputation, are the prerequisite for socially building a growing trust and the consequent strengthening of the insurance culture.

A new vision based on the concept that rights and democracy should never be taken for granted, requires commitment, dedication and sacrifice, in order to make a people build a better future for their country and give opportunities to their citizens and young people. In order to hold democracy, however, it is necessary to have intermediate bodies, which, with renewed passion, accept the challenge of outlining the greatest possible future. At that point, a renewed public commitment may also arise with the aim of financing a new general taxation.

The Italian healthcare sector after the Covid-19 pandemic will be in continuous evolution and will be subject to considerable risk.

The challenge ahead of us is to build a win/win scheme. This implies "a great commitment for the industry, which must be a loyal and professional actor - and for the supervision, which must be able to accompany the change and intercept and remove noncompliant conduct." 9

Public actors with their independence and foresight have a responsibility to respond with democracy to the needs of the market.

After Covid-19, the new competitive conditions and the real competitive advantages of global and national operators will emerge and they will propose to manage the risks of the future.

In the next social context there will be "agile" work, many new professions. A different social solidarity and the need for targeted savings will spread.

In the health emergency, the State is committed to promoting every appropriate initiative and has imposed precise behaviour's aimed at protecting the health of all its citizens. What is needed is the same spirit, the sustained initiative of the social partners, especially the Trade Union, and a great sense of responsibility, in order to organically address the problem of welfare in the third millennium.

Governing change is a must, today more than ever; it is no longer a simple objective but an urgent necessity in a new season of rights and duties, linked to the changing world of work.10 From the constructive dialogue to design tomorrow together, new creative

\footnotetext{
9 See link https://www.ivass.it/media/interviste/documenti/interventi/2020/22-10-2020-mlc-oic/MLC Intervento OIC 22.10.2020.pdf
}

${ }_{10}$ See link https://www.snfia.it/wp-content/uploads/Mozione-Finale-CDN-24-25-26-novembre-2020.pdf. 
solutions will have to emerge to shape a more just and united society, whose main objective is to put at the centre the essential needs of the human person and social cohesion.

Greater solidarity, combined with viable solutions based on collective governance mechanisms, the correct and ethical use of data and risk management tools - with a tax break based on the efficiency of spending throughout the country - may in the near future instil in Italian workers an adequate sense of security, protection and well-being, in order to bring back to our country the desire of growing together.

\section{REFERENCES}

1. Alberto Brambilla, Le scomode verità su tasse, pensioni, sanità e lavoro, Solferino, 2020.

2. Coviello Antonio, D'Antonio Carmine, Di Trapani Giovanni, The mission of the insurance sector in welfare policies - in Rivista elettronica di diritto, economia, management Anno IX, n. 3/2019 Publisher: ClioEdu - Lecce

3. ISSN: 2039-4926

4. https://www.clioedu.it/marketplace/elenco-completo/item/rivista-elettronica-di-diritto-economiamanagement-n-3-2019

5. Coviello Antonio, D’Antonio Carmine - Risk Management Sanitario: governo dei rischi e coperture assicurative nel welfare italiano -, in Journal of advanced health care Print

6. Publisher: Ordine TSRM PSTRP NA-AV-BN-CE - Napoli. ISSN: 2612-1344

7. http://www.cnr.it/prodotto/i/407630

8. Forum Ania Consumatori- CENSIS, Gli scenari del welfare. From precautionary cash to protection. Franco Angeli 2019.

9. IntesaSanPaolo RBM Salute, IX Rapporto sulla sanità pubblica, privata e intermediata, Annialità 2019 e 2020.

10. ISBN: 978-88-944209-9-9

11. IVASS, Statistical Bulletin Year VII - n. 19 - December 2020, Insurance Business in the health sector (2014-2019) https://www.ivass.it/pubblicazioni-e-statistiche/statistiche/bollettino-statistico/index.html?com.dotmarketing. htmlpage. language $=3$

12. ISSN 2421-3004 (online)

13. "WELFARE DAY 2019” in NotizieSnfia Anno XXIV - N. 91 Third Quarter 2019. 